\title{
RESEARCH
}

Open Access

\section{Characterization of stable hypoxia- preconditioned dental pulp stem cells compared with mobilized dental pulp stem cells for application for pulp regenerative therapy}

Mohammed Zayed ${ }^{1,2+}$, Koichiro lohara $^{1+}$, Hideto Watanabe ${ }^{3}$, Mami Ishikawa $^{4}$, Michiyo Tominaga $^{1}$ and Misako Nakashima ${ }^{1,4^{*}}$

\begin{abstract}
Background: Dental pulp stem cells (DPSCs) have been developed as a potential source of mesenchymal stem cells (MSCs) for regeneration of dental pulp and other tissues. However, further strategies to isolate highly functional DPSCs beyond the colony-forming methods are required. We have demonstrated the safety and efficacy of DPSCs isolated by G-CSF-induced mobilization and cultured under normoxia (mobilized DPSCS, MDPSCs) for pulp regeneration. The device for isolation of MDPSCs, however, is not cost-effective and requires a prolonged cell culture period. It is well known that MSCs cultured under hypoxic-preconditions improved MSC proliferation activity and stemness. Therefore, in this investigation, we attempted to improve the clinical utility of DPSCs by hypoxiapreconditioned DPSCs (hpDPSCs) compared with MDPSCs to improve the potential clinical utility for pulp regeneration in endodontic dentistry.

Methods: Colony-forming DPSCs were isolated and preconditioned with hypoxia in a stable closed cultured system and compared with MDPSCs isolated from the individual dog teeth. We examined the proliferation rate, migration potential, anti-apoptotic activity, and gene expression of the stem cell markers and angiogenic/neurotrophic factors. Trophic effects of the conditioned medium (CM) were also evaluated. In addition, the expression of immunomodulatory molecules upon stimulation with IFN- $\gamma$ was investigated. The pulp regenerative potential and transplantation safety of hpDPSCs were further assessed in pulpectomized teeth in dogs by histological and immunohistochemical analyses and by chemistry of the blood and urine tests.

(Continued on next page)
\end{abstract}

\footnotetext{
* Correspondence: misako@ncgg.go.jp

${ }^{\dagger}$ Mohammed Zayed and Koichiro lohara contributed equally to this work.

${ }^{1}$ Research Institute, Department of Stem Cell Biology and Regenerative

Medicine, National Center for Geriatrics and Gerontology, 7-430, Morioka,

Obu, Aichi 474-8511, Japan

${ }^{4}$ Air Water Group, Aeras Bio Inc., Kobe, Hyogo 650-047, Japan

Full list of author information is available at the end of the article
}

(c) The Author(s). 2021 Open Access This article is licensed under a Creative Commons Attribution 4.0 International License, which permits use, sharing, adaptation, distribution and reproduction in any medium or format, as long as you give appropriate credit to the original author(s) and the source, provide a link to the Creative Commons licence, and indicate if changes were made. The images or other third party material in this article are included in the article's Creative Commons licence, unless indicated otherwise in a credit line to the material. If material is not included in the article's Creative Commons licence and your intended use is not permitted by statutory regulation or exceeds the permitted use, you will need to obtain permission directly from the copyright holder. To view a copy of this licence, visit http://creativecommons.org/licenses/by/4.0/ The Creative Commons Public Domain Dedication waiver (http://creativecommons.org/publicdomain/zero/1.0/) applies to the data made available in this article, unless otherwise stated in a credit line to the data. 
(Continued from previous page)

Results: hpDPSCs demonstrated higher proliferation rate and expression of a major regulator of oxygen homeostasis, HIF-1a, and a stem cell marker, CXCR-4. The direct migratory activity of hpDPSCs in response to G-CSF was significantly higher than MDPSCs. The CM of hpDPSCs stimulated neurite extension. However, there were no changes in angiogenic, migration, and anti-apoptotic activities compared with the CM of MDPSCs. The expression of immunomodulatory gene, PTGE was significantly upregulated by IFN gamma in hpDPSCs compared with MDPS Cs. However, no difference in nitric oxide was observed. The regenerated pulp tissue was quantitatively and qualitatively similar in hpDPSC transplants compared with MDPSC transplants in dog teeth. There was no evidence of toxicity or adverse events of the hpDPSC transplantation.

Conclusions: These results demonstrated that the efficacy of hpDPSCs for pulp regeneration was identical, although hpDPSCs improved stem cell properties compared to MDPSCs, suggesting their potential clinical utility for pulp regeneration.

Keywords: Dental pulp stem cells, Hypoxia, Prime condition, Pulp regeneration, Dog teeth

\section{Background}

Dental pulp stem cells (DPSCs) are fibroblast-like adhesive cells characterized by colony-forming activities, selfrenewal, and multi-lineage differentiation potential similar to other mesenchymal stem cells (MSCs) [1]. DPSCs have remarkable biological properties including high proliferation and migration abilities, and immunomodulatory and angiogenic/neurotrophic effects of their secretome [2-4]. DPSCs can be readily isolated from the discarded teeth with no ethical issues [5]. Further, they may be stored in a stem cell bank. It is noteworthy that several preclinical/clinical studies have demonstrated the therapeutic potential of DPSCs for regeneration of various tissue diseases including ischemic brain injury, infarcted myocardium, muscular dystrophy, and in dentistry $[6,7]$.

The DPSCs have been isolated and cultured typically by colony-formation method [2]. We demonstrated that the regenerated pulp tissue was less in volume and mineralized after transplantation of unfractionated DPSCs compared with fractionated DPSC subfraction of $\mathrm{CD}_{105^{+}}$cells in the pulpectomized dog teeth [8]. The isolation methods by the flow cytometer or magnetic cell selection system device using the stem cell marker CD105 were not cost-effective in safety and efficacy for manufacturing clinical grade DPSCs. Thus, we have developed a novel isolation method based on ability of DPSC subfractions to mobilized by granulocyte colonystimulating factor (G-CSF) [9]. The mobilized DPSCs (MDPSCs) showed higher expression of stem cell markers, higher trophic effects on anti-apoptosis, migration, angiogenesis, neurite extension, and immunomodulation, and higher pulp regenerative potential $[9,10]$. Our clinical study further demonstrated the clinical grade human MDPSCs are safe and efficacious for complete pulp regeneration [11]. The device for isolation of MDPSCs, however, is not cost effective and the cell culture period is prolonged. Thus, the cost-effective method and safety of the isolation and processing of good manufacturing practice (GMP) grade DPSC subsets with high-regeneration potential remains a challenge, and we have addressed this in the present investigation.

Significant attempts have been made to modify the microenvironment of directed tissues through management of MSC behavior and outcome in vitro by seeding density, passage number, coating surfaces, and threedimensional scaffolds [12]. Moreover, preconditioning with specific biological factors or cytokines, genetic modification, and hypoxic treatment have been suggested to improve MSC properties [13]. Above all, oxygen $\left(\mathrm{O}_{2}\right)$ concentration is one of the most important critical factors to play an ultimate role in cell growth and metabolism. Currently, in vitro cultures of MSCs are typically done in a $95 \%$ air supplemented with $5 \%$ of carbon dioxide $\left(\mathrm{CO}_{2}\right)$. The endogenous physiological oxygen concentration is critical for the optimal outcome of cell growth and differentiation [14]. There are many studies reported a negative impact of ambient $\mathrm{O}_{2}$ concentration on cultured MSCs, including decreased proliferation rate, DNA damage, and early senescence [15, 16]. On the other hand, hypoxia was reported to have a profound effect on MSCs to increase proliferation rate [15], plasticity [17], engraftment [18], reduction of reactive oxygen species [19], and expression of chemokine receptors and migration [20]. A range of 3 to $6 \% \mathrm{O}_{2}(20$ to $40 \mathrm{mmHg}$ ) has been identified in a physiological state of adult organs and tissues [21]. The definite oxygen concentration in situ, however, varies mostly on the vascularization and metabolic activity of the tissue [22]. The dental pulp has a relatively high blood flow, well irrigated, giving a range of 2 to $6 \%$ of partial pressure of oxygen level [23]. We recently demonstrated that low oxygen supplementation (5\%) is ultimate to enhance proliferation rate, stem cell properties, and trophic effects of secretome in cultured DPSCs [24]. We further developed a closed culture system in which only one 
octahedron container was used for expansion from the primary to the third passage of culture with the stable oxygen concentration and $\mathrm{pH}$. Our preliminary results demonstrated that the colony-forming human DPSCs proliferated better both in $5 \% \mathrm{O}_{2}$ and $3 \% \mathrm{O}_{2}$ compared to those in $20 \% \mathrm{O}_{2}$ condition and the stem cell properties of DPSCs cultured between $5 \% \mathrm{O}_{2}$ and $3 \% \mathrm{O}_{2}$ conditions were similar.

The aim of this study was to examine whether DPSCs isolated and preconditioned with stable $5 \% \mathrm{O}_{2}$, named hpDPSCs could have optimal stem cell properties and pulp regenerative potential. Thus, we attempted to develop the cost-effective and safe methods for improving GMP-grade cell processing of DPSC subsets instead of G-CSF-induced mobilization method. We evaluated proliferation rate, migration activity, gene expression of stem cells markers, immunomodulatory, and trophic factors. The various trophic effects of the CM were also examined and compared to MDPSCs. Furthermore, pulp regenerative potential compared to MDPSCs and transplantation safety of hpDPSCs were examined in pulpectomized teeth in dogs. These analyses have led us to propose that the hpDPSCs could be used as a potential clinical replacement of the MDPSCs for optimal pulp regenerative cell therapy.

\section{Methods}

\section{Culture of hpDPSCs}

All animal procedures were approved by the Animal Care and Use Committee of the National Center for Geriatrics and Gerontology, Research Institute (permission \#30-19, \#31-17) and the Aichi Medical University (permission \#2019-92, \#2020-92) and Shin Nippon Biomedical Laboratories Ltd (permission \#IACUC860-017). All procedures and methods were performed in accordance with relevant guidelines and regulations. Upper third incisors, a total of 12 teeth from 6 young female beagle dogs (Kitayama Lab, Ina, Japan) at 1 year old were used for isolation of MDPSCs and hpDPSCs. For hpDPSCs, isolated DPSCs were cultured in a stable hypoxic condition in a closed container with a regular octahedron having $21 \mathrm{~cm}^{2}$ of each surface (Animal Stem Cell, Tokyo, Japan), in which humidified gas mixtures of the composition of $5 \% \mathrm{O}_{2}-5 \% \mathrm{CO}_{2}-90 \% \mathrm{~N}_{2}$ were flushed. The $\mathrm{pH}$ of the hypoxic cultures was adjusted by adding HEPES buffer (Gibco, Dublin, Ireland) at a final concentration of $25 \mathrm{mM}$ to Dulbecco's modified Eagle's medium (DMEM) (Sigma Aldrich, MO, USA) supplemented with $10 \%$ fetal bovine serum (FBS, GE Healthcare, Little Chalfont, England). Each sensor chip (SP-LG1-SA-S, and SPPSt3-SA, PreSens, Regensburg, Germany) was patched on the bottom of the container inside, respectively, and the $\mathrm{pH}$ and $\mathrm{O}_{2}$ concentration in the DMEM and the air were measured by non-contact $\mathrm{pH}$ meter $(\mathrm{pH}-1 \mathrm{SMA}$
LG1; PreSens) and non-contact oxygen analyzer (OXY1SMA trace, PreSens).

The primary colony-derived DPSCs were expanded in the same one surface of the octahedron container at the 2nd passage of culture and further cultured in the all surface of the container by rotating $45^{\circ}$ every $1 \mathrm{~min}$ by a rotary equipment (Biomedica Solution, Ibaraki, Japan) at the 3rd passage. These hpDPSCs were detached and cryopreserved at $1 \times 10^{6}$ cells $/ \mathrm{mL}$ in the stem cell banker (ZENOAQ Co., LTD., Fukushima, Japan) for further experiments.

MDPSCs based on their migratory response to G-CSF (Neutrogin, Chugai Pharmaceutical, Tokyo, Japan) were isolated at the 2nd passage from colony-derived primary DPSCs and cultured according to our previous study [9]. In brief, colony-derived primary DPSCs were seeded into the upper chambers (permeable support $8.0 \mu \mathrm{m}$ polycarbonate membrane $6.5 \mathrm{~mm}$ Insert, Corning, Lowell, MA) which inserted in 24 well plate contained with DMEM supplemented with $10 \% \mathrm{FBS}$ and $100 \mathrm{ng} / \mathrm{ml} \mathrm{G-CSF}$. The membrane was modified chemically (Toray Industries, Co., Ltd., Tokyo) to prevent cell attachment. After $48 \mathrm{~h}$, the chamber was removed, and medium was changed into DMEM with 10\% FBS. Once cells reached $60-70 \%$ confluence, they were detached and subcultured.

\section{Doubling time}

The population doubling time was calculated by counting the cell number from the 2nd expansion to the 3rd expansion. The cells were stained with trypan blue and the viable cells were counted with a hemocytometer.

\section{Real-time reverse transcription-polymerase chain reaction analysis}

For real-time reverse transcription-polymerase chain reaction (RT-PCR) analysis, total RNA was extracted using TRIzol (Thermo Fisher Scientific, Waltham, MA, USA) from hpDPSCs and MDPSCs at the 5th to 6th passage of culture. First-strand cDNA syntheses were performed from $1 \mu \mathrm{g}$ of total RNA by reverse transcription using ReverTra Ace- $\alpha$ (Toyobo, Tokyo, Japan). Real-time PCR amplifications were performed using canine HIF- $1 \alpha$ (forward) 5'-ACTGATGACCAACAACTTGAGG-3' and (reverse) 5' -TTTGGAGTTTCAGAAGCAGGTA-3'. Canine stem cell markers, angiogenic/neurotrophic factors, and immunomodulatory factors were used as our previous studies [8, 25]. All primers were labeled with Power SYBR Green PCR Master Mix (Applied Biosystems, Foster City, CA, USA) in 7500 RT-PCR system (Applied Biosystems). The relative mRNA expression was examined in hpDPSCs to MDPSCs after normalizing with $\beta$ actin. 


\section{Migration activity of hpDPSCs and MDPSCs}

To determine the migratory activity in response to GCSF, $1 \times 10^{5}$ of hpDPSCs or MDPSCs were seeded in $100 \mu \mathrm{l}$ of DMEM on top of an insert membrane with 8$\mu \mathrm{m}$ pore size in 24-well plates (Corning-Transwell- polycarbonate membrane cell culture inserts, Sigma-Aldrich, Missouri, USA). The lower compartment medium contained 2\% FBS and was supplemented with or without G-CSF $(100 \mathrm{ng} / \mathrm{ml})$. After $24 \mathrm{~h}$, cells were removed from the top of the membrane with cotton swabs. The migrating cells on the lower surface of the membrane were fixed with 95\% methanol and stained with 0.5\% Giemsa stain for $15 \mathrm{~min}$. After washing, the stained cells were counted in 4 fields per well under an inverted bright-field microscope (Leica, 6000B-4, Leica Microsystems $\mathrm{GmbH}$, Wetzlar, Germany) at $\times 100$ magnification.

\section{The effect of the $\mathrm{CM}$ on angiogenesis and neurite extension}

For collecting the conditioned media $(\mathrm{CM})$, the hpDPSCs and MDPSCs were cultured in the complete culture medium. The medium was changed into DMEM without serum at $70 \%$ confluence, and the $\mathrm{CM}$ collected $48 \mathrm{~h}$ later and concentrated by Amicon Ultra-15 Centrifugal Filter (Millipore, Billerica, MA, USA). To compare the stimulative effect of the $\mathrm{CM}$ on endothelial cell differentiation, human umbilical vein endothelial cells (HUVEC, clone 7F3415, Lonza) were seeded on Matrigel (BD Biosciences, San Jose, CA, USA) in DMEM containing $2 \% \mathrm{FBS}, 5 \mu \mathrm{g} / \mathrm{ml}$ heparin (Lonza, Basel, Switzerland), $5 \mu \mathrm{g} / \mathrm{ml}$ ascorbic acid (Lonza), and $5 \mu \mathrm{g} / \mathrm{ml}$ hydrocortisone (Lonza) supplemented with the CM $(5 \mu \mathrm{g} / \mathrm{ml}$ proteins). The mean length of networks of cords and tubelike structures was measured $5 \mathrm{~h}$ after cultivation under the inverted microscope (Leica) using ImageJ software (version 1.52, imagej.nih.gov). The same experiment was performed with $100 \mathrm{ng} / \mathrm{ml} \mathrm{G-CSF}$ (Peprotech, London, $\mathrm{UK}$ ) as a positive control.

For examining the effect on neurite outgrowth, human neuroblastoma cell line (TGW, clone JCRB 0618, Health Science Research Resources Bank, Japan) was cultured without serum overnight and then stimulated with the $\mathrm{CM}(5 \mu \mathrm{g} / \mathrm{ml}$ proteins) for $24 \mathrm{~h}$. The mean neurite length was measured under the inverted microscope using ImageJ software (version 1.52, imagej.nih.gov). The same experiment was performed with a $50 \mathrm{ng} / \mathrm{ml}$ neurotrophin-3 (Peprotech, London, UK) as a positive control.

\section{The combinatorial effect of the CM with G-CSF on migration}

The migratory effects of the CM of hpDPSCs or MDPS Cs together with G-CSF were compared with those of the CM only. Periodontal ligament cells (PDLCs) from young dog (10 months old) were isolated according to the previous study [26]. PDLCs were cultured in DMEM supplemented with $10 \%$ FBS and cryopreserved at the 4th to 7th passage of culture. For the migratory activity, $1 \times 10^{5}$ of PDLCs were seeded in $100 \mu \mathrm{l}$ of DMEM on top of the insert membrane. The lower compartment medium containing 2\% FBS were supplemented with $5 \mu \mathrm{g} / \mathrm{ml} \mathrm{CM}$ with or without $100 \mathrm{ng} / \mathrm{ml}$ of G-CSF. GCSF only and $2 \%$ FBS only were used as a positive control and as a negative control respectively. After $24 \mathrm{~h}$, the migrating cells were stained as previously described.

\section{Anti-apoptotic activity of the CM}

To examine the anti-apoptotic effect of G-CSF, hpDPSCs or MDPSCs were incubated with $500 \mathrm{nM}$ staurosporine (Sigma) in DMEM supplemented with $100 \mu \mathrm{g} / \mathrm{ml}$ of G-CSF. After $3 \mathrm{~h}$, cells were harvested and the activity of caspase- 3 was measured using APOPCYTOTM Caspase-3 Colorimetric Assay Kit (Medical and Biological Laboratories, Nagoya, Japan) according to the manufacturer's protocol.

For examining the combinatorial effect of the $\mathrm{CM}$ with G-CSF on anti-apoptotic activity, canine PDLCs were cultured in DMEM with staurosporine and $50 \mu \mathrm{g} / \mathrm{ml}$ of CM with or without $100 \mathrm{ng} / \mathrm{ml}$ of G-CSF and the activity was measured as previously described.

\section{Immunomodulation activity upon stimulating with interferon gamma (IFN- - )}

hpDPSCs and MDPSCs were stimulated with IFN- $\gamma$ (PROSPEC, East Brunswick NJ, USA) at a concentration of $20 \mathrm{ng} / \mathrm{ml}$ in DMEM without serum for $24 \mathrm{~h}$ according to the previous studies $[27,28]$ with slight modification. Non-stimulated cells were used as a control. RNA was extracted using Trizol, and the CM was collected and concentrated. The mRNA expression of immunosuppressive markers IDO, TGF- $\beta 1, P T G E$, and $I L-6$ as our previous study [29] was examined by RT-PCR. The concentration of nitric oxide (NO) was examined by measuring its stable end product, nitrite, in the CM using a Griess reagent (Promega Corporation, Madison, WI, USA) according to manufacturer's protocol. Absorbance at $540 \mathrm{~nm}$ was measured by microplate reader (SpectraMax Gemini XPS/EM, Molecular Devices, San Jose, CA, USA), and nitrite concentrations were calculated using a standard nitrite curve.

\section{Comparison of trophic factor mRNA expression between the rotating and stationary conditions}

After validation the $\mathrm{pH}$ and $\mathrm{O}_{2}$ concentration, we examined the effect of the rotating culture. Freshly isolated pulp cells from an upper fourth incisor from 1-year-old dog were plated into three containers, and the cultured hpDPSCs were further divided into the two containers at 
the 3rd passage of culture, respectively; $1 / 9$ of the total cells was plated in the stationary condition at one surface of the octahedron closed container with $5 \% \mathrm{O}_{2}$ and the remaining $8 / 9$ was plated in the rotating condition at eight surfaces of the container with $5 \% \mathrm{O}_{2}$. The trophic factor mRNA expression was compared by RT-PCR between the stationary and rotating conditions.

\section{Transplantation of hpDPSCs and MDPSCs into pulpectomized teeth in dogs}

The upper first and second incisors, a total of 12 teeth from 3 young female beagle dogs (Kitayama Lab, Ina, Japan) at 1 year old were used. Transplantation of hpDPSCs or MDPSCs at $5 \times 10^{5}$ cells together with GCSF (Neutrogin) in $20 \mu \mathrm{l}$ of atelocollagen scaffold (1\% atelocollagen implant; Koken, Tokyo, Japan) was performed for pulp regeneration in the pulpectomized teeth as described previously with slight modification [10]. The teeth were extracted at 4 weeks after cell transplantation. Histological examination of the regenerated tissue was performed in the paraffin sections ( $5 \mu \mathrm{m}$ in thickness) of the teeth. The regenerated tissue was outlined in on-screen image of the histological preparations of each 4 sections $(n=6)$ by a binocular microscope (Leica, M 205 FA Leica Microsystems, Wetzlar, Germany), and its relative amount to the root canals was determined by using Leica Application Suite software (Leica, version 3.4.1). For neovascularization and innervation analyses, Fluorescein Griffonia (Bandeiraea) Simplicifolia Lectin 1/fluorescein-galanthus nivalis (snowdrop) or anti-PGP9.5 (Ultra Clone) (1: 10, 000) were used, respectively. The ratios of newly formed capillary area and neurite extension area to the regenerated pulp area were measured respectively by Dynamic cell count BZ-HIC (KEYENCE, Osaka, Japan).

For evaluation of safety of the hpDPSC transplantation, each upper left second incisor was extracted from 3 dogs at 9 to 12 months old in the Shin Nippon Biomedical Laboratories Ltd. and transported to the $\mathrm{Na}$ tional Center for Geriatrics and Gerontology to isolate and culture hpDPSCs. The cryopreserved hpDPSCs were transported by air to the animal facility in the Shin Nippon Biomedical Laboratories Ltd. and autologously transplanted at $5 \times 10^{5}$ cells into pulpectomized upper right second incisors $(n=3)$ as described previously. The dogs were observed in clinical signs, daily food consumption, and weekly weight change for toxicology assessment. Urinalysis was performed by Clinitek AtlasXL (Sparton Medical Systems, Strongsville, OH, USA) at 2 and 4 weeks. Blood tests and blood chemistry examinations were performed by ADIVIA 120 (Siemens Healthcare Diagnostics Manufacturing Ltd., Erlangen, Germany) and by JCA-BM6070 (Japan Electron Optical Laboratory, Tokyo, Japan), respectively, at 1, 2, and 4 weeks. One dog without cell transplantation was used as a control. The transplanted teeth were extracted, and all organs were weighed and macroscopically examined at 4 weeks followed by euthanization. They were further examined histopathologically in the paraffin sections stained with hematoxylin and eosin (HE).

\section{Statistical analysis}

All the results were expressed as the means \pm standard deviation (SD). Student's $t$ test was used for a two-group comparison. For the migration, angiogenesis, neurite extension, anti-apoptotic, and immunomodulation assays, a one-way analysis of variance (ANOVA) was used followed by a Tukey's comparisons post hoc test using SPSS 25.0 (IBM, Armonk, NY). A $p$ value less than 0.05 was considered statistically significant.

\section{Results}

Maintenance of $\mathrm{pH}$ and $\mathrm{O}_{2}$ concentration

The $\mathrm{pH}$ and $\mathrm{O}_{2}$ concentrations of the hypoxic cell cultures were monitored for 29 days, demonstrating that $\mathrm{pH}$ value was maintained between 6.85 and 7.01 and $\mathrm{O}_{2}$ concentration value was maintained at 5.4-6.5 and 5.15.9 in the DMEM liquid and in the air of the container, respectively (Supplemental Fig. 1).

\section{Decreased doubling time of hpDPSCs}

The doubling time of hpDPSCs was significantly lower compared to MDPSCs $(p<0.05)$ (Fig. 1a). There was little difference in the cell morphology between hpDPSCs and MDPSCs, showing stellate or spindle-shaped morphology at the 3rd passage of culture (Fig. 1b). The total culture period of hpDPSCs was shorter $(12 \pm 0.5$ days) compared with that of MDPSCs (20 \pm 2 days).

\section{Expression of stem cell markers, trophic factors, and immunomodulatory genes}

The mRNA expression levels of a major regulator of oxygen homeostasis, $H I F-1 \alpha$, were two times higher in hpDPSCs compared to MDPSCs $(p<0.05)$ (Fig. 1c), indicating hypoxic effect. A stem cell marker, CXCR4 was also significantly higher in hpDPSCs (Fig. 1d), suggesting more enrichment of the stem cells or establishing of the stem cell properties. However, other markers Oct4, STAT3, and NANOG were similarly expressed. Expression of angiogenic factor, GM-CSF was significantly higher in hpDPSCs compared to MDPSCs $(p<0.05)$. However, VEGF expression was similar. Moreover, expression of neurotrophic factors, $B D N F$ and $N G F$ were significantly higher in hpDPSCs $(p<0.05)$, but not GDNF (Fig. 1d). In addition, the expression level of a pulp marker, TRH-DE, was similar between hpDPSCs and MDPSCs (Fig. 1d). 
a

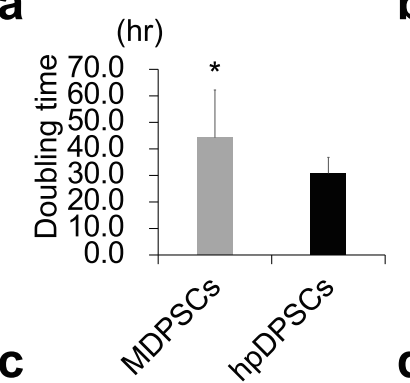

b

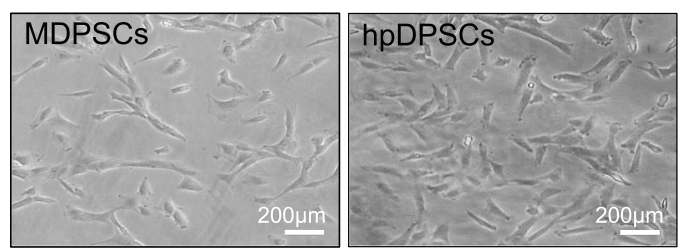

d

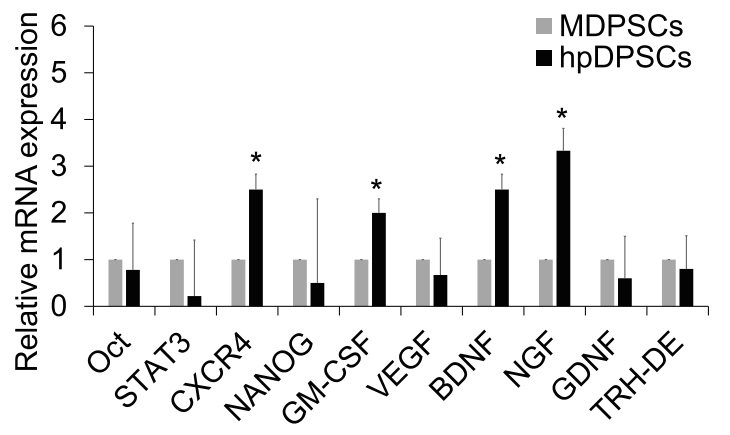

e

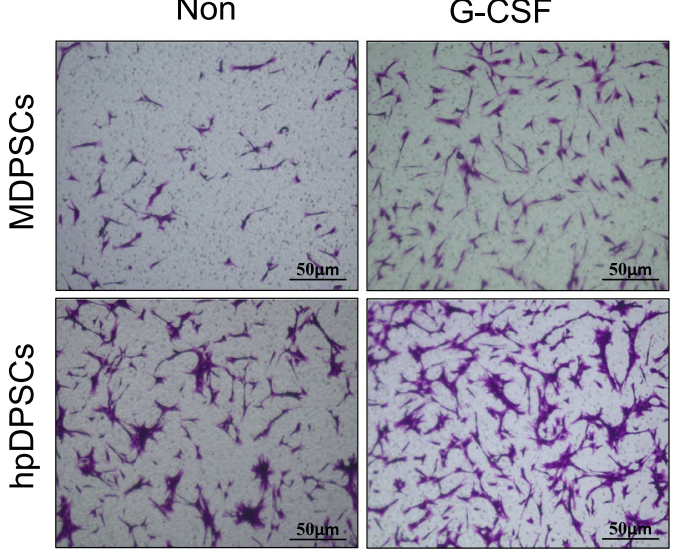

$\mathbf{f}$

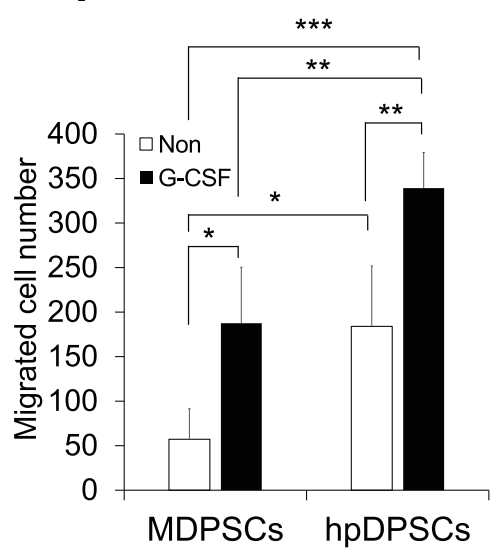

Fig. 1 Stem cell properties of hpDPSCs compared with MDPSCs. a Proliferation activity, doubling time. ${ }^{*} p<0.05$. b A representative images of the morphology. c, d Gene expression of HIF-1a, stem cell markers, trophic factors, and immunomodulatory markers. ${ }^{*} p<0.05$. e Migration activity in response to G-CSF. $\mathbf{f}$ Statistical analysis of migration activity after $24 \mathrm{~h} .{ }^{*} p<0.05,{ }^{* *} p<0.01$, and ${ }^{* * *} p<0.001$. All data are expressed as the means \pm standard deviation $(n=3)$

\section{Enhanced migration activity of hpDPSCs}

Next, the migration activity of hpDPSCs and MDPSCs was examined. hpDPSCs were able to migrate at the higher rate without G-CSF compared to MDPSCs $(p<$ 0.05) (Fig. 1e, f). It is noteworty that the migration of hpDPSCs with G-CSF was significantly higher compared with MDPSCs with G-CSF ( $p<0.01$ ) (Fig. 1f). There were also significant differences between $2 \%$ FBS only as a control and 2\% FBS together with G-CSF both in hpDPSCs and MDPSCs $(p<0.01$, and $p<0.05$, respectively) (Fig. 1e, f). These results suggested that hpDPSCs might have the higher G-CSF receptor expression than MDPSCs.
Higher effect of hpDPSC CM on neurite extension, comparable effect on angiogenesis and migration The CM of hpDPSCs and MDPSCs was further used to examine enhanced angiogenic and neurite extension activities. There was no difference in the angiogenic activity between the hpDPSC CM and the MDPSC CM, although the angiogenic activities of those CM were significantly higher compared with control (Fig. 2a, b). On the other hand, the hpDPSC CM demonstrated a significantly higher stimulatory effect on neurite outgrowth in human neuroblastoma TGW cells than the MDPSC CM $(p<0.05)$ (Fig. 2c, d). 
a
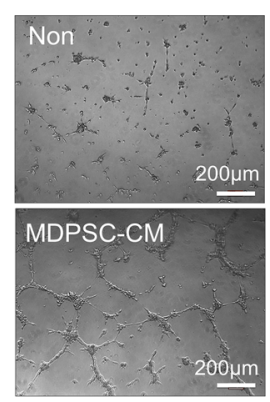

C
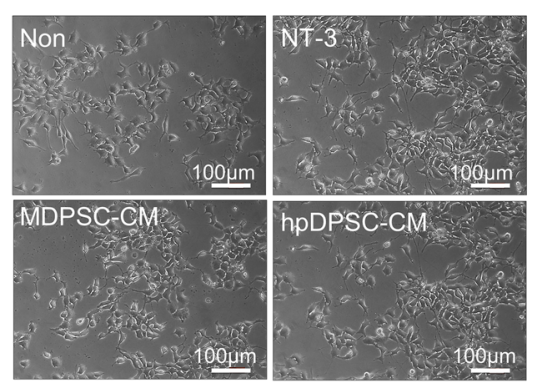

e

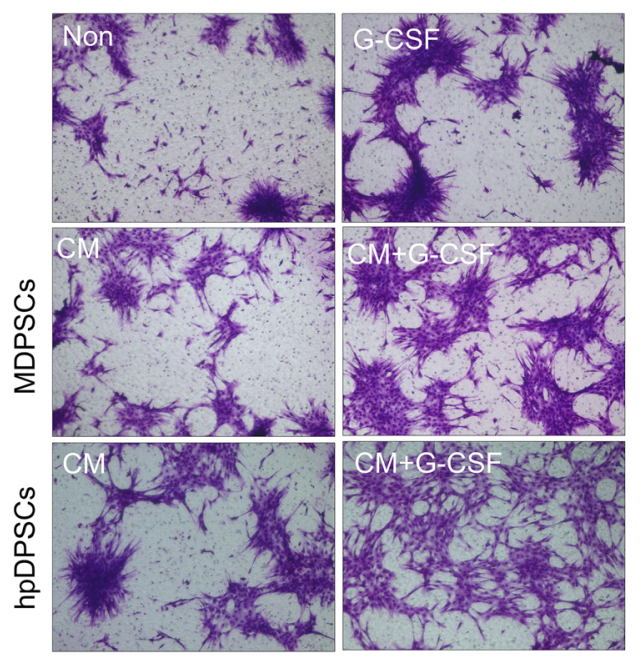

b

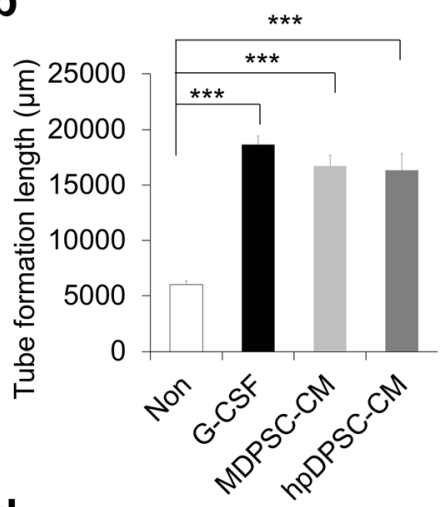

d
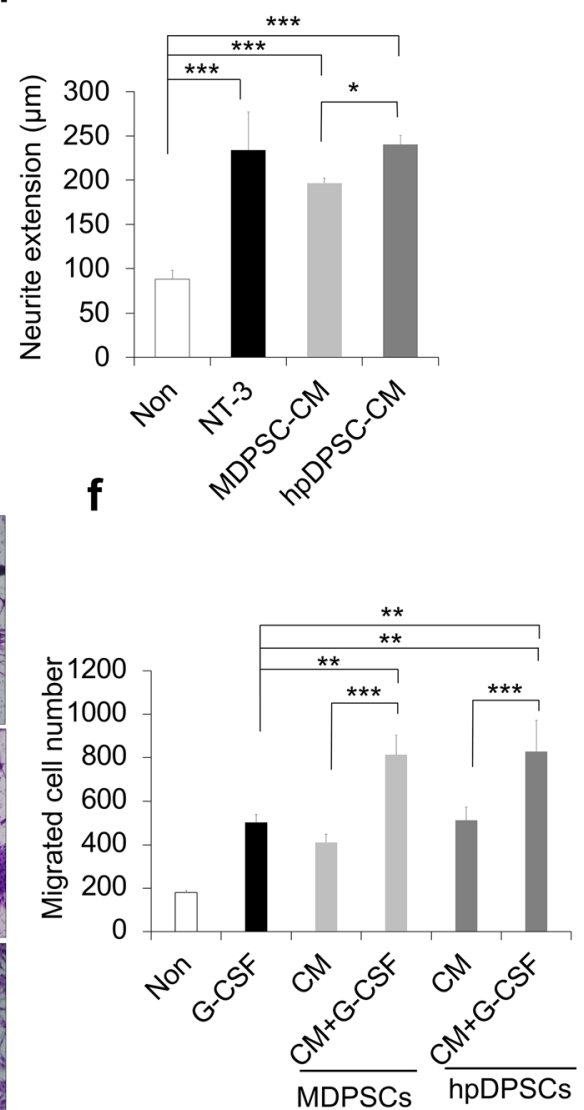

Fig. 2 Trophic effects of the conditioned medium (CM) of hPDPSCs compared with MDPSCs. a Enhanced effect of the CM on angiogenic activity of HUVEC, showing network formation after $5 \mathrm{~h}$. b Statistical analysis of the total tube length. ${ }^{*} p<0.05$ and ${ }^{* * *} p<0.001$. c Stimulatory effect of the CM on neurite outgrowth of TGW cell line. $\mathbf{d}$ Statistical analysis of neurite length in the different conditions. e Migration activity of periodontal ligament cells toward the CM with or without G-CSF $(100 \mathrm{ng} / \mathrm{ml})$. $\mathbf{f}$ Statistical analysis of migration activity after $24 \mathrm{~h} .{ }^{* *} p<0.01$ and ${ }^{* * *} p<0.001$. All data are expressed as the means \pm standard deviation $(n=3)$

The effect of the hpDPSC CM and the MDPSC CM both together with G-CSF on migration activity was further examined in canine PDLCs. Both the CM with G-CSF showed the higher migration activities compared to the CM only $(p<0.001)$ and G-CSF only $(p<0.01) \quad$ (Fig. 2e, f). However, no significant difference between the hpDPSC CM and the MDPSC $\mathrm{CM}$, and between the hpDPSC CM with G-CSF and the MDPSC CM with G-CSF was observed (Fig. 2e, f). These results demonstrated the similar combinatorial effect of the hpDPSC CM to the MDPSC CM together with G-CSF. 


\section{Comparable effect of hpDPSC CM on anti-apoptosis}

We examined the anti-apoptotic effect of G-CSF in the hpDPSCs compared with the MDPSCs by quantifying caspase-3 activity. The increased caspase-3 activities after treatment with staurosporine were similarly reduced by supplement with G-CSF in the hpDPSCs to the MDPSCs (Fig. 3a). The in vitro trophic effects of hPDPSC CM and MDPSC CM with or without G-CSF on anti-apoptosis were further assessed. Both the CM with or without G-CSF significantly inhibited apoptosis in the staurosporine-treated canine PDLCs $(p<0.05)$ (Fig. 3b), without showing any significant difference between the hpDPSC CM and the MDPSC CM with and without G-CSF.

\section{Comparable effect of hpDPSC CM on immunomodulatory activity}

Under the hemostatic condition, the expression of immunosuppressive factors, IDO, PTGE, and TGF- $\beta$ was no significant difference between in hpDPSCs and MDPSCs (Fig. 3c). To address whether priming with IFN- $\gamma$ could regulate the immunomodulation of hpDPSCs and MDPSCs, we further stimulated the cells with IFN- $\gamma$ for $24 \mathrm{~h}$. The immunosuppression genes $I D O, P T G E$, and TGF- $\beta$ were significantly upregulated both in the stimulated hpDPSCs and MDPSCs compared with those in the unstimulated (Fig. 3d-g). However, there was no significant difference between hpDPSCs and MDPSCs except for PTGE. The expression of PTGE was 2.7 times higher in hpDPSCs compared with MDPS Cs $(p<0.05)$ (Fig. 3e). Production of NO in the hpDPSC $\mathrm{CM}$ and the MDPSC CM did not show any changes when stimulated with IFN- $\gamma$ (Fig. 3h). These results demonstrate that hpDPSCs and MDPSCs have a similar immunosuppressive function when stimulated with proinflammatory cytokines.

\section{Little effect of rotating condition on trophic factor expression}

There was little effect of rotating condition on the trophic factor expression in hpDPSCs compared with the stationary condition (Table 1). These results suggested that the present findings of the improved stem cell properties of hpDPSCs were due to hypoxic condition, not due to rotating condition.

\section{Similar pulp regenerative potential}

Next, the difference in a pulp regenerative potential between the hpDPSCs and the MDPSCs was examined in the dog pulpectomized teeth. The morphologically similar pulp tissue (Fig. 4a, b), well-vascularized (Fig. 4h), and well-innervated (Fig. 4k) loose connective tissue was regenerated at 4 weeks after hpDPSC transplantation with G-CSF as shown after MDPSC transplantation
(Fig. 4d, e, i, l). There was little infiltration of inflammatory cells and no internal absorption (Fig. 4a, d). The osteoblastic cells confined in the mineralized tissue along the dentinal wall, and/or odontoblastic cells aligning to the newly formed mineralized tissue were observed both in the transplants of the hpDPSCs and the MDPSCs (Fig. 4c, f). There was no significant difference in the ratio of the regenerated pulp area to the total root canal area between the hpDPSC transplants and the MDPSC transplants (Fig. 4g). Furthermore, no significant difference in neovascularization (Fig. 4j) and reinnervation (Fig. $4 \mathrm{~m}$ ) was demonstrated between the hpDPSC transplants and the MDPSC transplants.

\section{No adverse effects}

No adverse effects on appearance, clinical signs, food consumption, and body weight were detected by toxicology assessment for 4 weeks after the hpDPSC transplantation. Also, no increase of white blood cell and platelet numbers (Table 2) was observed indicating no immunoreaction toward the transplanted cells. Serum and urine chemistry parameters showed values within normal ranges for 4 weeks (Table 2). No abnormalities were observed in any organ or tissues assessed by histopathological examinations at 4 weeks. These results demonstrate that hpDPSC transplantation is safe for pulp regeneration.

\section{Discussion}

The isolated DPSCs from adult teeth are usually limited in their number; thus, it is essential for pulp regenerative cell therapy to expand the isolated primary DPSCs without altering their stem cell properties. Therefore, providing a suitable microenvironment/niche similar to their physiological condition is important. We previously showed that MDPSCs have a high regenerative potential $[9,30]$. However, it is a challenge for the utility of MDPSCs to be cost-effective and safe for approval as a medical device. It has been demonstrated that MSCs cultured under hypoxic condition could improve their regenerative potential in variety of tissues [31, 32]. Improved potential of the hypoxia-preconditioned MSCs has been reported for different clinical applications including spinal cord and lung injury, hindlimb ischemia, and immune-deficient models due to improving their secretion of reparative factors $[33,34]$ and initiating autophagy [35]. Thus, in this study, to further develop the isolation and culture method without using the MDPSC isolation device for DPSC subsets with high-regenerative potential, DPSCs were cultured under stable hypoxic (5\%) and $\mathrm{pH}$ condition which were confirmed by noncontact oxygen analyzer and $\mathrm{pH}$ meter. The hpDPSCs were examined whether it could replace MDPSCs in pulp regenerative cell therapy. Transplantation of 


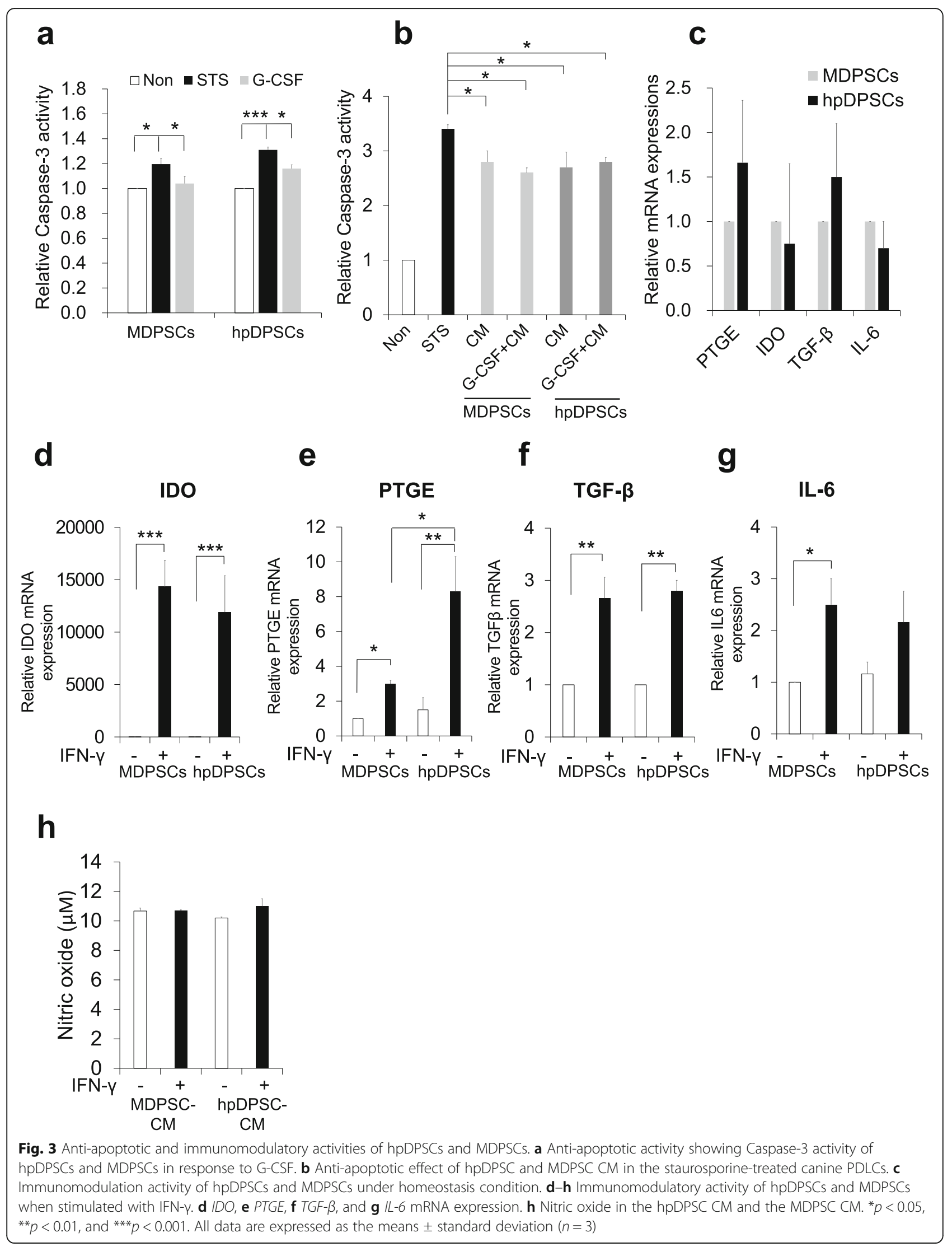


Table 1 The effect of the rotating condition on the trophic factor expression compared with the stationary condition in hPDPSCs by RT-PCR

\begin{tabular}{ll}
\hline & Rotating/stationary \\
\hline GM-CSF & $1.3 \pm 0.4$ \\
CXCR4 & $1.0 \pm 0.4$ \\
NGF & $1.9 \pm 0.9$ \\
BDNF & $0.9 \pm 0.2$ \\
IDO & $0.5 \pm 0.2$ \\
PTGE & $0.9 \pm 0.1$ \\
TGF- $\beta 1$ & $1.1 \pm 0.2$ \\
IL-6 & $0.9 \pm 0.1$ \\
\hline
\end{tabular}

All data are expressed as the means $\pm \mathrm{SD}(n=3)$. The experiment was repeated three times, and one representative experiment is presented

hpDPSCs with G-CSF exhibited a high pulp regenerative potential in vivo similar to MDPSCs with G-CSF without significant difference and no evidence of toxicity or adverse events. We previously demonstrated the combinatorial effect of MDPSCs with G-CSF for pulp regeneration on localization and engraftment of transplanted cells in the root canal, migration, and antiapoptosis [10]. We recently demonstrated a significantly higher expression of G-CSF receptor, G-CSFR in human hpDPSCs compared with MDPSCs $(68.2 \%$, 38.3\%, respectively) (unpublished data). In the present in vitro study, hpDPSCs showed higher proliferation rate, shorter culture period, and higher migration activity compared with MDPSCs in the presence of G-CSF. The hpDPSCs were survived similarly to MDPSCs in the presence of G-CSF. These findings suggest that the higher G-CSFR expression of the hpDPSCs might be one of the promising factors in cell properties for pulp regenerative cell therapy using with G-CSF. Thus, hpDPSCs have the advantage in clinical application for pulp regenerative therapy.

Oxygen is an important factor in the microenvironment of the cells for proliferation and differentiation [36]. A level of 3 to $6 \%$ of $\mathrm{O}_{2}$ was found in the physiological condition of adult organs and tissues including dental pulp tissue [21]. HIF- $1 \alpha$ is a master transcription factor in the low oxygen partial pressure and represents a hypoxia key downstream effector which is involved in proliferation, angiogenesis, metabolism, and apoptosis

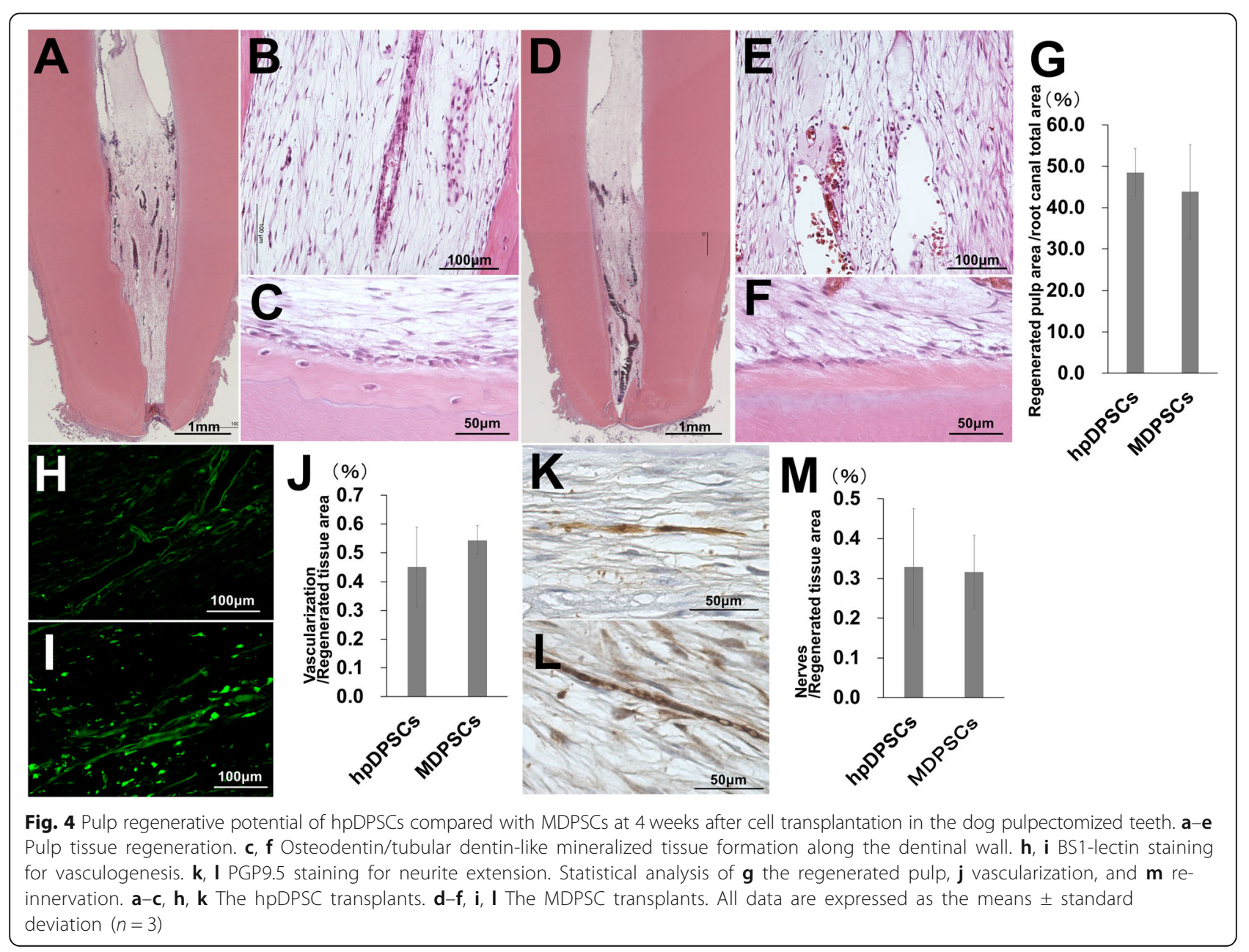




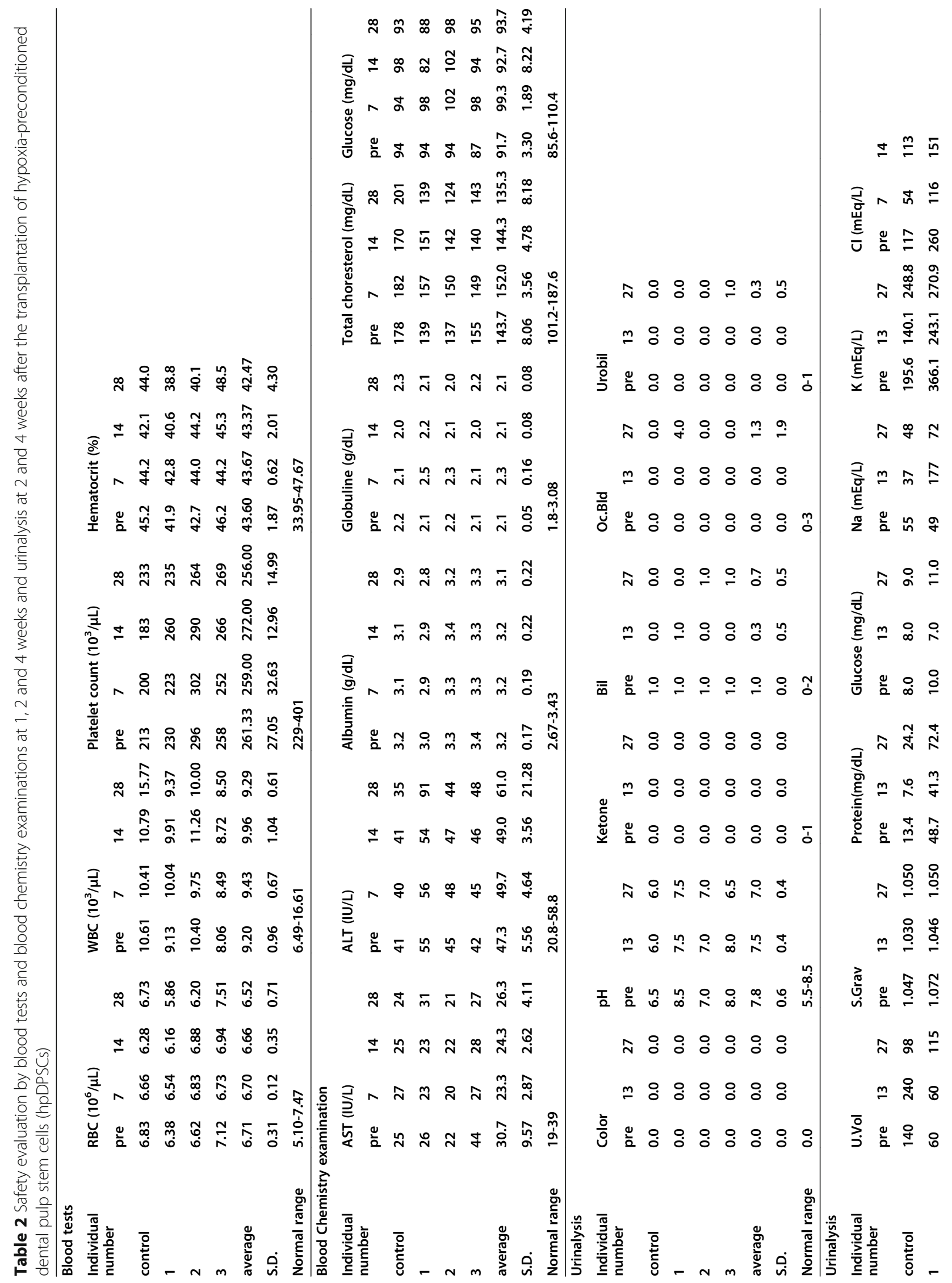




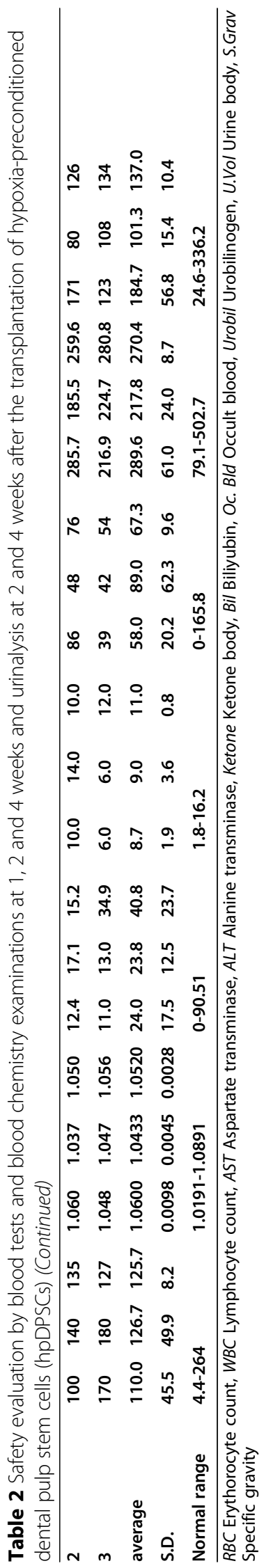


[37, 38]. Moreover, HIF- $1 \alpha$ is playing an important role in the metabolism and behavior of MSCs to maintain the biological functions and survival of transplanted stem cells [38]. It has been shown that hypoxia $\left(5 \% \mathrm{O}_{2}\right)$ improved the characteristics of human MSCs such as increased proliferation rate, inhibition of senescence, and enhanced regenerative potential [34, 39]. Recently, DPSCs under hypoxic condition exhibited a higher proliferation rate and increased stem cell properties [24, 40]. Incubation of DPCs at $1 \% \mathrm{O}_{2}$ for $24 \mathrm{~h}$ could enhance proliferation rate and increased expression level of HIF-1 and CXCR4 in human dental pulp cells [41]. We previously demonstrated that MDPSCs were enriched for stem cells, having higher angiogenic and neurotrophic potential, and pulp regenerative potential compared to non-isolated DPSCs $[9,25]$. Also, non-isolated human DPSCs demonstrated that $5 \% \mathrm{O}_{2}$ significantly increased the proliferation rate, migration ability, and expression of stem cell markers (CXCR4 and G-CSFR) by flowcytometry compared with normoxia [24]. The present investigation demonstrated a higher gene expression of HIF- $1 \alpha$ in hpDPSCs in $5 \% \mathrm{O}_{2}$ condition compared with MDPSCs in normoxia. Therefore, hypoxic preconditioning or activating expression of HIF- $1 \alpha$ is important to improve DPSC therapeutic potential. Proliferation rate and mRNA expression level of CXCR4 were also significant higher in hpDPSCs compared to MDPSCs. These findings suggested that low $\mathrm{O}_{2}$ microenvironment may be essential to maintain the stem cell properties of DPSCs.

Angiogenesis, neurite extension, and migration of resident stem cells from the surrounding tissue of the teeth have been shown to play an important role in mediating the functional recovery of pulp tissue after pulpectomy $[10,42]$. Several reports indicate that hypoxic condition of MSCs can enhance vascular tube formation [43] and neurogenesis [44]. The previous in vivo studies of hypoxia-preconditioned MSCs demonstrated enhanced angiogenic cytokine secretion in a murine hind-limb ischemia model [45]. Hypoxic cultures of DPSCs have previously demonstrated higher expression of angiogenic/ neurotrophic factors, VEGF, NGF, and BDNF compared with normoxia and its $\mathrm{CM}$ stimulated neurite extension [24]. In the present study, hpDPSCs demonstrated a significantly higher gene expression of an angiogenic factor, GM-CSF, compared to MDPSCs, although there was no difference in VEGF expression and tube formation. Moreover, hpDPSCs enhanced neurite extension with increased expression of neurotrophic factors, $N G F$ and $B D N F$ which are some of major factors responsible for the innervation of pulp [46]. There was no difference in angiogenic/neurogenic potential between hpDPSCs and MDPSCs in the present dog pulpectomized teeth. Thus, these findings suggest that hpDPSCs may replace MDPSCs by the enhanced angiogenic/neurotrophic potential.
It has been shown that DPCs and PDLCs cultured under hypoxic condition increased the stimulatory effect of the CM on migration [41, 47, 48]. The hpDPSC CM exhibited similar migratory activity toward G-CSF to MDPSC CM. These findings suggest that a similar migratory activity of hpDPSCs in respect to releasing migration paracrine factors to MDPSCs may be one of important factors for pulp regeneration.

The hypoxic condition significantly reduces apoptosis of MSCs in vitro [49]. Enhanced survival and retention of hypoxic preconditioned MSCs are reported after injection in a spinal cord injury [50], muscle [51], and a cerebral infarction [35]. The role of HIF-1 $\alpha$ in cell viability and anti-apoptosis of MSCs has been suggested [52]. Furthermore, the upregulation of secretory proteins involved in inhibition of apoptosis including thymosin-beta, elongation factor 2, and ganoderan under hypoxic condition are demonstrated in MSCs under hypoxic conditions [52]. In the current study, the hpDPSCs expressed HIF-1 $\alpha$ significantly higher than MDPSCs and could reduce apoptosis by G-CSF similarly to the MDPSCs. The CM of the hpDPSCs also reduced apoptotic activity of PDLCs, a representative of the resident cells in the tissue surrounding the teeth, similarly to the CM of MDPSCs. These findings suggested that the transplanted hpDPSCs together with G-CSF may well-survive, retain, and enhance survival of migrating resident stem cells similarly as the MDPSCs.

The effect of hypoxia ( 1 and $5 \% \mathrm{O}_{2}$ ) on the immunomodulatory function of adipose tissue-derived MSCs has been studied, demonstrating an upregulation of the immunomodulatory molecules upon stimulation with proinflammatory cytokines [53]. Interferon (IFN) $-\gamma$ is a potent pro-inflammatory cytokine that produced by multiple immune cells to plays an important role in both innate and adaptive immunity. We evaluated the immunomodulation effect of hpDPSCs under stimulation with IFN- $\gamma$ compared to MDPSCs. IFN- $\gamma$ enhanced the immunomodulatory functions of hpDPSCs and MDPSCs and induced the expression of IDO, PTGE, TGF- $\beta$, and $I L-6$, with no significant difference except for PTGE. These results indicated that both hpDPSCs and MDPS Cs have similar immunomodulatory effect under proinflammatory cytokine stimuli to improve their functionality and therapeutic capacity for pulp regeneration.

\section{Conclusions}

In conclusion, the present investigation demonstrated that the hpDPSCs exhibited the higher proliferation and migration abilities, although anti-apoptotic and immunomodulatory properties were identical. The efficacy of hpDPSCs for pulp regeneration was identical to that of MDPSCs. Thus, these results suggested the potential clinical utility of hpDPSCs for pulp regeneration. 


\section{Supplementary Information}

The online version contains supplementary material available at https://doi. org/10.1186/s13287-021-02240-w.

\section{Additional file 1: Supplemental Fig. 1.}

\section{Abbreviations}

BDNF: Brain-derived neurotrophic factor; CM: Conditioned medium: DPSCs: Dental pulp stem cell; G-CSF: Granulocyte colony-stimulating factor; GDNF: Glial cell-derived neurotrophic factor; GM-CSF: Granulocyte monocyte colony-stimulating factor; GMP: Good manufacturing practice; IDO: Indoleamine 2,3-dioxygenase; IFN- $\gamma$ : Interferon gamma; MDPS C: Mobilized dental pulp stem cell; MSCs: Mesenchymal stem cells; NGF: Nerve growth factor; NO: Nitric oxide; PDLCs: Periodontal ligament cells; PTGE: Prostaglandin E synthase; RT-PCR: Real-time quantitative polymerase chain reaction; TGF $\beta 1$ : Transforming growth factor-beta1; TRH-DE: Thyrotropin releasing hormone degrading enzyme; VEGF: Vascular endothelial growth factor; hpDPSCs: Hypoxia-preconditioned dental pulp stem cells

\section{Acknowledgements}

We thank Narifumi Kishida (Air Water Group) and Tatsumi Okada (Biomedica Solution) for providing the rotary equipment.

\section{Authors' contributions}

Mohammed Zayed and Koichiro lohara: conception and design, collection and/or assembly of data, data analysis, and manuscript writing. Hideto Watanabe: data analysis, interpretation, and collection of data. Mami Ishikawa: collection of data and data analysis. Michiyo Tominaga: collection of data and data analysis. Misako Nakashima: conception and design, financial support, manuscript writing, and final approval of the manuscript. The authors read and approved the final manuscript.

\section{Funding}

This work was supported by a Joint Research and Development between the National Center for Geriatrics and Gerontology and Air Water Inc.

\section{Availability of data and materials}

All data generated or analyzed during this study are included in this published article and its supplemental information files.

\section{Declarations}

\section{Ethics approval}

All animal procedures were approved by the Animal Care and Use Committee of the National Center forGeriatrics and Gerontology, Research Institute (permission \#30-19, \#31-17) and the Aichi Medical University (permission \#2019-92, \#2020-92) and Shin Nippon Biomedical Laboratories Ltd (permission \#IACUC860-017).

\section{Consent for publication}

Not applicable.

\section{Competing interests}

The corresponding author Nakashima M receives research support from the Air Water Inc. A detailed listing of Nakashima's financial disclosures is available at https:/www.awi.co.jp/business/medical/med_guideline/med_ guideline_info.html and https://www.ncgg.go.jp/research/annualreport/ documents/2019nenpo1.pdf. No other author has reported a potential conflict of interest relevant to this article.

\section{Author details}

${ }^{1}$ Research Institute, Department of Stem Cell Biology and Regenerative Medicine, National Center for Geriatrics and Gerontology, 7-430, Morioka, Obu, Aichi 474-8511, Japan. ${ }^{2}$ Department of Surgery, College of Veterinary Medicine, South Valley University, Qena 83523, Egypt. ${ }^{3}$ Institute for Molecular Science of Medicine, Aichi Medical University, Nagakute, Aichi 480-1195, Japan. ${ }^{4}$ Air Water Group, Aeras Bio Inc., Kobe, Hyogo 650-047, Japan.
Received: 2 November 2020 Accepted: 24 February 2021

Published online: 29 May 2021

\section{References}

1. Dominici M, Le Blanc K, Mueller I, Slaper-Cortenbach I, Marini F, Krause D, et al. Minimal criteria for defining multipotent mesenchymal stromal cells. The international society for cellular therapy position statement. Cytotherapy. 2006;8(4):315-7.

2. Gronthos S, Brahim J, Li W, Fisher LW, Cherman N, Boyde A, DenBesten P, Robey PG, Shi S. Stem cell properties of human dental pulp stem cells. J Dent Res. 2002;81(8):531-5.

3. Li Z, Jiang CM, An S, Cheng Q, Huang YF, Wang YT, et al. Immunomodulatory properties of dental tissue-derived mesenchymal stem cells. Oral Dis. 2014;20(1):25-34.

4. Mead B, Logan A, Berry M, Leadbeater W, Scheven BA. Paracrine-mediated neuroprotection and neuritogenesis of axotomised retinal ganglion cells by human dental pulp stem cells: comparison with human bone marrow and adipose-derived mesenchymal stem cells. Plos One. 2014;9(10):e109305.

5. Egusa H, Sonoyama W, Nishimura M, Atsuta I, Akiyama K. Stem cells in dentistry--part I: stem cell sources. J Prosthodont Res. 2012;56(3):151-65.

6. Yamada Y, Nakamura-Yamada S, Kusano K, Baba S. Clinical potential and current progress of dental pulp stem cells for various systemic diseases in regenerative medicine: a concise review. Int J Mol Sci. 2019;20(5):1132.

7. Syed-Picard FN, Du Y, Lathrop KL, Mann MM, Funderburgh ML, Funderburgh JL. Dental pulp stem cells: a new cellular resource for corneal stromal regeneration. Stem Cells Transl Med. 2015;4(3):276-85.

8. Iohara K, Imabayashi K, Ishizaka R, Watanabe A, Nabekura J, Ito M, Matsushita K, Nakamura H, Nakashima M. Complete pulp regeneration after pulpectomy by transplantation of cd105+ stem cells with stromal cellderived factor-1. Tissue Eng A. 2011;17(15-16):1911-20.

9. Murakami M, Horibe H, lohara K, Hayashi Y, Osako Y, Takei Y, et al. The use of granulocyte-colony stimulating factor induced mobilization for isolation of dental pulp stem cells with high regenerative potential. Biomaterials. 2013;34(36):9036-47.

10. Iohara K, Murakami M, Takeuchi N, Osako Y, Ito M, Ishizaka R, et al. A novel combinatorial therapy with pulp stem cells and granulocyte colonystimulating factor for total pulp regeneration. Stem Cells Transl Med. 2013; 2(7):521-33

11. Nakashima M, lohara K, Murakami M, Nakamura H, Sato Y, Ariji Y, Matsushita K. Pulp regeneration by transplantation of dental pulp stem cells in pulpitis: a pilot clinical study. Stem Cell Res Ther. 2017:8(1):61.

12. MacQueen L, Sun Y, Simmons CA. Mesenchymal stem cell mechanobiology and emerging experimental platforms. J R Soc Interface. 2013;10(84): 20130179.

13. Seo Y, Shin T-H, Kim H-S. Current strategies to enhance adipose stem cell function: an update. Int J Mol Sci. 2019;20(15):3827.

14. Antoniou ES, Sund S, Homsi EN, Challenger LF, Rameshwar P. A theoretical simulation of hematopoietic stem cells during oxygen fluctuations: prediction of bone marrow responses during hemorrhagic shock. Shock. 2004;22(5):415-22

15. Estrada JC, Albo C, Benguria A, Dopazo A, Lopez-Romero P, CarreraQuintanar $L$, et al. Culture of human mesenchymal stem cells at low oxygen tension improves growth and genetic stability by activating glycolysis. Cell Death Differ. 2012;19(5):743-55.

16. Fehrer C, Brunauer R, Laschober G, Unterluggauer H, Reitinger S, Kloss F, Gully C, Gassner R, Lepperdinger G. Reduced oxygen tension attenuates differentiation capacity of human mesenchymal stem cells and prolongs their lifespan. Aging Cell. 2007;6(6):745-57.

17. Basciano L, Nemos C, Foliguet B, de Isla N, de Carvalho M, Tran N, Dalloul A. Long term culture of mesenchymal stem cells in hypoxia promotes a genetic program maintaining their undifferentiated and multipotent status. BMC Cell Biol. 2011;12:12.

18. Leroux L, Descamps B, Tojais NF, Seguy B, Oses P, Moreau C, et al. Hypoxia preconditioned mesenchymal stem cells improve vascular and skeletal muscle fiber regeneration after ischemia through a wnt4-dependent pathway. Mol Ther. 2010;18(8):1545-52.

19. Semenza GL. Regulation of oxygen homeostasis by hypoxia-inducible factor 1. Physiology (Bethesda). 2009;24:97-106.

20. Liu H, Liu S, Li Y, Wang X, Xue W, Ge G, Luo X. The role of sdf-1-cxcr4/cxcr7 axis in the therapeutic effects of hypoxia-preconditioned mesenchymal stem cells for renal ischemia/reperfusion injury. PLoS One. 2012;7(4):e34608. 
21. Kozam G. Oxygen tension of rabbit incisor pulp. J Dent Res. 1967;46(2):352-8.

22. Ward JP. Oxygen sensors in context. Biochim Biophys Acta. 2008;1777(1):114.

23. Mas-Bargues C, Sanz-Ros J, Román-Domínquez A, Inglés M, GimenoMallench L, El Alami M et al. Relevance of oxygen concentration in stem cell culture for regenerative medicine. Int J Mol Sci. 2019;20(5):1195. https:// doi.org/10.3390/ijms20051195.

24. Ahmed NE-MB, Murakami M, Kaneko S, Nakashima M. The effects of hypoxia on the stemness properties of human dental pulp stem cells (dpscs). Sci Rep. 2016;6:35476.

25. Murakami M, Hayashi Y, lohara K, Osako Y, Hirose Y, Nakashima M. Trophic effects and regenerative potential of mobilized mesenchymal stem cells from bone marrow and adipose tissue as alternative cell sources for pulp/ dentin regeneration. Cell Transplant. 2015;24(9):1753-65.

26. Iohara K, Zayed M, Takei Y, Watanabe H, Nakashima M. Treatment of pulpectomized teeth with trypsin prior to transplantation of mobilized dental pulp stem cells enhances pulp regeneration in aged dogs. Front Bioeng Biotechnol. 2020;8:983. https://doi.org/10.3389/fbioe.2020.00983.

27. Wang D, Wang S, Huang S, Zhang Z, Yuan X, Feng X, Lu L, Sun L. Serum ifn- $\gamma$ predicts the therapeutic effect of mesenchymal stem cells transplantation in systemic lupus erythematosus patients. Stem Cells Trans Med. 2017:6(9):1777-85.

28. Du J, Liu A, Zhu R, Zhou C, Su H, Xie G, Deng Y, Xu X. The different effects of ifn- $\beta$ and ifn- $\gamma$ on the tumor-suppressive activity of human amniotic fluid-derived mesenchymal stem cells. Stem Cells Int. 2019;2019:4592701.

29. Iohara K, Utsunomiya S, Kohara S, Nakashima M. Allogeneic transplantation of mobilized dental pulp stem cells with the mismatched dog leukocyte antigen type is safe and efficacious for total pulp regeneration. Stem Cell Res Ther. 2018;9(1):116.

30. Nakayama H, lohara K, Hayashi Y, Okuwa Y, Kurita K, Nakashima M. Enhanced regeneration potential of mobilized dental pulp stem cells from immature teeth. Oral Dis. 2017;23(5):620-8.

31. Ma T, Grayson WL, Fröhlich M, Vunjak-Novakovic G. Hypoxia and stem cellbased engineering of mesenchymal tissues. Biotechnol Prog. 2009;25(1):3242.

32. Tsai C-C, Yew T-L, Yang D-C, Huang W-H, Hung S-C. Benefits of hypoxic culture on bone marrow multipotent stromal cells. Am J Blood Res. 2012; 2(3):148-59.

33. Silva LHA, Antunes MA, Dos Santos CC, Weiss DJ, Cruz FF, Rocco PRM. Strategies to improve the therapeutic effects of mesenchymal stromal cells in respiratory diseases. Stem Cell Res Ther. 2018;9(1):45.

34. Noronha NC, Mizukami A, Caliári-Oliveira C, Cominal JG, Rocha JLM, Covas DT, Swiech K, Malmegrim KCR. Priming approaches to improve the efficacy of mesenchymal stromal cell-based therapies. Stem Cell Res Ther. 2019;10(1):131.

35. Hu C, Zhao L, Wu D, Li L. Modulating autophagy in mesenchymal stem cells effectively protects against hypoxia- or ischemia-induced injury. Stem Cell Res Ther. 2019:10(1):120.

36. Das $\mathrm{R}$, Jahr $\mathrm{H}$, van Osch GJ, Farrell E. The role of hypoxia in bone marrowderived mesenchymal stem cells: considerations for regenerative medicine approaches. Tissue Eng Part B Rev. 2010;16(2):159-68.

37. Påhlman S, Mohlin S. Hypoxia and hypoxia-inducible factors in neuroblastoma. Cell Tissue Res. 2018;372(2):269-75.

38. Lee HJ, Jung YH, Choi GE, Kim JS, Chae CW, Han HJ. Role of hif1 a regulatory factors in stem cells. Int J Stem Cells. 2019;12(1):8-20.

39. Kwon SY, Chun SY, Ha Y-S, Kim DH, Kim J, Song PH, et al. Hypoxia enhances cell properties of human mesenchymal stem cells. Tissue Eng Regen Med. 2017;14(5):595-604.

40. Werle SB, Chagastelles $P$, Pranke $P$, Casagrande $L$. The effects of hypoxia on in vitro culture of dental-derived stem cells. Arch Oral Biol. 2016;68:13-20.

41. Gong QM, Quan JJ, Jiang HW, Ling JQ. Regulation of the stromal cellderived factor-1alpha-cxcr4 axis in human dental pulp cells. J Endod. 2010; 36(9):1499-503.

42. Nakashima M, lohara K. Regeneration of dental pulp by stem cells. Adv Dent Res. 2011;23(3):313-9.

43. Almeria C, Weiss R, Roy M, Tripisciano C, Kasper C, Weber V, Egger D. Hypoxia conditioned mesenchymal stem cell-derived extracellular vesicles induce increased vascular tube formation in vitro. Front Bioeng Biotechnol. 2019;23;7:292. https://doi.org/10.3389/fbioe.2019.00292.

44. Gugliandolo A, Diomede F, Scionti D, Bramanti P, Trubiani O, Mazzon E. The role of hypoxia on the neuronal differentiation of gingival mesenchymal stem cells: a transcriptional study. Cell Transplant. 2019;28(5):538-52.
45. Lee JH, Yoon YM, Lee SH. Hypoxic preconditioning promotes the bioactivities of mesenchymal stem cells via the hif-1a-grp78-akt axis. Int J Mol Sci. 2017;18(6):1320

46. Fried K, Lillesaar C, Sime W, Kaukua N, Patarroyo M. Target finding of pain nerve fibers: neural growth mechanisms in the tooth pulp. Physiol Behav. 2007:92(1-2):40-5.

47. Xiao Z, Han Y, Zhang Y, Zhang X. Hypoxia-regulated human periodontal ligament cells via wnt/beta-catenin signaling pathway. Medicine (Baltimore). 2017:96(16):e6562.

48. Kanafi MM, Ramesh A, Gupta PK, Bhonde RR. Influence of hypoxia, high glucose, and low serum on the growth kinetics of mesenchymal stem cells from deciduous and permanent teeth. Cells Tissues Organs. 2013;198(3): 198-208.

49. Bader AM, Klose K, Bieback K, Korinth D, Schneider M, Seifert M, et al. Hypoxic preconditioning increases survival and pro-angiogenic capacity of human cord blood mesenchymal stromal cells in vitro. PLoS One. 2015; 10(9):e0138477.

50. Oh JS, Ha Y, An SS, Khan M, Pennant WA, Kim HJ, Yoon DH, Lee M, Kim KN. Hypoxia-preconditioned adipose tissue-derived mesenchymal stem cell increase the survival and gene expression of engineered neural stem cells in a spinal cord injury model. Neurosci Lett. 2010;472(3):215-9.

51. Beegle J, Lakatos K, Kalomoiris S, Stewart H, Isseroff RR, Nolta JA, Fierro FA. Hypoxic preconditioning of mesenchymal stromal cells induces metabolic changes, enhances survival, and promotes cell retention in vivo. Stem Cells. 2015;33(6):1818-28.

52. Lv B, Li F, Fang J, Xu L, Sun C, Han J, et al. Hypoxia inducible factor $1 a$ promotes survival of mesenchymal stem cells under hypoxia. Am J Transl Res. 2017;9(3):1521-9.

53. Roemeling-Van Rhijn M, Mensah F, Korevaar S, Leijs M, van Osch G, IJzermans $J$ et al. Effects of hypoxia on the immunomodulatory properties of adipose tissue-derived mesenchymal stem cells. Front Immunol. 2013;18; 4:203. https://doi.org/10.3389/fimmu.2013.00203.

\section{Publisher's Note}

Springer Nature remains neutral with regard to jurisdictional claims in published maps and institutional affiliations.

Ready to submit your research? Choose BMC and benefit from:

- fast, convenient online submission

- thorough peer review by experienced researchers in your field

- rapid publication on acceptance

- support for research data, including large and complex data types

- gold Open Access which fosters wider collaboration and increased citations

- maximum visibility for your research: over $100 \mathrm{M}$ website views per year

At $\mathrm{BMC}$, research is always in progress.

Learn more biomedcentral.com/submissions 